\title{
Coastal Zone Facing Climate Change: Knowledge Towards New Solutions
}

\section{Roshan T Ramessur*}

Department of Chemistry, Faculty of Science, University of Mauritius

Keywords: Coastal zone management; Submarine groundwater discharge; Coastal vulnerability; Climate change

\section{Introduction}

Humanity's impact on the Earth system has become comparable to planetary-scale geological processes, such as ice ages. Consensus is growing that we have driven the planet into a new epoch, the Anthropocene, in which many Earth-system processes and the living fabric of ecosystems are now dominated by human activities. That the Earth has experienced large-scale, abrupt changes in the past indicates that it could experience similar changes in the future. This recognition has led researchers to take the first step to identify planetary and regional thresholds, and boundaries that, if crossed, could generate unacceptable environmental and social change [1]. Galvanized by the United Nations Conference on Environment and Development meeting of 1992, there has been a search for methods to build capacity of coastal nations and communities to manage their coastal and estuarine resources in a sustainable manner. Countries are now increasingly being affected mostly by hydro-meteorological hazards and disasters, namely, floods, mass movements (e.g. erosion, landslides and siltation), heat waves, wildfires, tropical cyclones, tsunamis, swells and dust storms $[2,3]$. Research now demonstrates that the continued functioning of the Earth system, as it has supported the well-being of human civilization in recent centuries is at risk. Without urgent action, we could face threats to water, food, biodiversity and other critical resources: these threats risk intensifying economic, ecological and social crises, creating the potential for a humanitarian emergency on a global scale. Nutrients are now the largest pollution problem in coastal marine ecosystems globally, and in the US, some $60 \%$ of estuaries are moderately to severely degraded, primarily from nutrients like nitrates and phosphates [4-7]. Developing economies tend to be dominated by resource-based activities with degrading and overexploitive uses of land, water and other coastal resources, with disruption of environmental processes through degradation of environmental quality and loss of critical terrestrial and aquatic habitats, leading to serious deleterious impacts on the health and productivity of coastal ecosystems. Studies have also showed that estuaries are particularly vulnerable to nutrient over-enrichment and trace metal contamination [8-12].

The principle of interdisciplinarity and an integrative approach of all the problems encountered in the coastal zone have to be implemented. The coastal zone should be viewed as one complex multidisciplinary entity with the various conflicting uses and activities taking place within the zone, and there is an urgent need to further protect sensitive marine and coastal areas besides salt marshes, coral reefs, such as wetlands, islets, sea grass beds and mangroves, and encourage the use of environmentally cleaner technology in industries, including the recycling of wastes. Existing coastal inventorying enabling coastal zone management can benefit from advancement in GIS application and coastal engineering.

There is now a need to synthesize and organize data into a common DPSIR framework, and manuscripts in the special issue in coastal engineering and management will focus on coastal vulnerability requiring climate change adaptation, which aim to cover observed and expected changes of material fluxes from drainage basins/ islands, including transboundary impact assessment considering the ocean and atmospheric inputs. Interconnected issues require interconnected solutions. Rapid scientific and technological progress can provide potential solutions-if adopted in timely manner-to reduce the risk of deleterious consequences for societies everywhere. But technological innovation alone will not be enough. We can transform our values, beliefs and aspirations towards sustainable prosperity. New mechanisms to facilitate an interactive dialogue on global sustainability among the various stakeholders and the policy-making community at different scales. Such interactions should be designed to bring societal relevance and trust to science-policy interfaces, and more effectively inform decision-making to keep pace with rapid global change.

\section{Conclusion}

The Special Issue in the Journal of Coastal Development on Coastal Engineering and Management will deal with papers with land-sea interactions and human dimensions of change in specific and vulnerable coastal regions, and harmonizing with descriptions of diverse coastal and ocean stakeholders and social players filling existing gaps in knowledge with data collection and scientific inquiries towards new coastal solutions. It will also include papers on coastal engineering, ecological, socio-economic and governance aspects to include Integrated Coastal and Ocean Management (ICOM) indicators, fisheries depletion, navigational routes, new recreation points, waste disposal sites, remotely sensed data and GIS database to provide information for sensible policy-making in the coastal zone. Based on this kind of information, Integrated Coastal and Ocean Management should be seen as an adaptive process of resource management for environmentally sustainable development once implemented, ICOM should not be expected to remain static, but should form an iterative mechanism continuously evolving and evaluating and eventually redefining its internal milestones regularly to meet the dynamic goals deriving from temporal and spatial changes that have to be made to the management objectives subject to changing demand, legislation and climate change.

\section{References}

1. (2012) State of the Planet Declaration: New Knowledge towards Solutions. In: Proceedings of the Planet under Pressure conference, London, UK.

2. Clark JR (1992) Integrated management of coastal zones. FAO Fisheries Technical Paper 327, Food and Agriculture Organization of the United Nations, Rome, Italy.

${ }^{*}$ Corresponding author: Roshan T Ramessur, Department of Chemistry, Faculty of Science, University of Mauritius, E-mail: ramessur@uom.ac.mu

Received September 04, 2013; Accepted September 06, 2013; Published September 12, 2013

Citation: Ramessur RT (2013) Coastal Zone Facing Climate Change: Knowledge Towards New Solutions. J Coast Dev 16: e103. doi: 10.4172/1410-5217.1000e103

Copyright: @ 2013 Ramessur RT. This is an open-access article distributed under the terms of the Creative Commons Attribution License, which permits unrestricted use, distribution, and reproduction in any medium, provided the original author and source are credited. 
Citation: Ramessur RT (2013) Coastal Zone Facing Climate Change: Knowledge Towards New Solutions. J Coast Dev 16: e103. doi: 10.4172/14105217.1000 e103

Page 2 of 2

3. Linden O (1995) Integrated coastal zone management in Eastern Africa including the Island states. Coastal Management Center, Philippines 371.

4. Kotecha P (2010) Climate change, adaptation and higher education: Securing our future. Southern African Regional Universities Association (SARUA), Africa.

5. Norse EA (1993) Global marine biológical diversity: A strategy for building conservation into decisión making. Center for Marine Conservation, Island Press, Washington, D.C., USA 383.

6. Tyrrell T, Law CS (1997) Low nitrate: phosphate ratios in the global ocean. Nature 387: 793-796.

7. Burnett WC, Aggarwal PK, Aureli A, Bokuniewicz H, Cable JE, et al. (2006) Quantifying submarine groundwater discharge in the coastal zone via multiple methods. Sci Total Environ 367: 498-543.

8. Povinec PP, Burnett WC, Beck A, Bokuniewicz H, Charette M, et al. (2012) Isotopic, geophysical and biogeochemical investigation of submarine groundwater discharge: IAEA-UNESCO intercomparison exercise at Mauritius Island. J Environ Radioact 104: 24-45.

9. Ramessur RT (2002) Anthropogenic driven changes with focus to the coasta zone of Mauritius, South-Western Indian Ocean. Regional Environmental Change 3: 99-106.

10. Ramessur RT (2010) Trace metal contamination in urbanized estuaries and implications of submarine groundwater discharge for coastal zone management in Mauritius. In: Natural and Man Made Disasters, Section-4, Vol 1, Chapter 16 Singh KK, Singh AK (Eds.), Times Press, New Delhi, India: 329-342.

11. Van Veen RJ, Stortelder PBM (1988) Research on contaminated sediments in the Netherlands. In: Wolf K, Van de Brink WJ, Colon FJ (Eds), Contaminated Soil, Academic Publishers, USA 1263-1275.

12. Waeles M, Riso RD, Le Corre P (2007) Distribution and seasonal changes of lead in an estuarine system affected by agricultural practices: The Penze estuary, NW France. Estuar Coast Shelf Sci Vol 74: 570-578. 